Mosul Journal of Nursing, Vol. 6, No. 1, 2018 ( 51-59 )

Mosul Journal of Nursing

www.mjn.mosuljournals.com

\title{
Assessment of Injection Safety Practice among nurses at Primary Health Care Centers in Mosul
}

Article information

Article history:

Received March 25, 2018

Accepted March 27, 2019

Available online May 28, 2021

DOI: 10.33899/mjn.2021.168249 @2020, College of Nursing, University of Mosul.

Creative Commons Attribution 4.0 International License https://mjn.mosuljournals.com/article_160082.html

Dr. Suha J. Abdul- Lateef ${ }^{1}$ Mohamed S . Jasim ${ }^{3}$

Mahmood H . Sulaiman ${ }^{2}$

\begin{abstract}
:
Background: safe injection practice is the practice that does not harm both health workers and recipient and not produce harmful waste products.
\end{abstract}

Aim: To determine the injection safety practice among nurses at primary health care centers in Mosul city.

Materials and method: a descriptive study was carried out to include a random sample of 45 nurses selected from 12 primary health care centers of both sides of the city left and right, tool of study depend on observational check list and interview questionnaire.

Results: The study diagnosed both safe and unsafe injection practices which were performed by nurses at their setting of work. Safe practice significantly performed as single use of syringes, using a lot of sizes of syringes, dispose syringes to safety box, close safety box tightly, send safety boxes to buried and incinerated safety boxes, avoid changing safety boxes, specify a team to follow up safety injection measures, continuing education and training on safety injection. Unsafe practice also diagnosed as: don`t washing hands after injection, don`t using gloves when they have skin

\footnotetext{
${ }^{1}$ Lecturer / College of Nursing / University of Mosul

${ }^{2}$ Instructor / College of Nursing / University of Mosul

${ }^{3}$ Instructor / College of Nursing / University of Mosul
} 
lesion, filling safety boxes to the top, dispose vials and ampoules to safety box. Poor vaccination coverage with hepatitis (B) vaccine among nurses. The study also found the only significant measures after exposure to needle stick injury were washing hands and notify about the exposure.

Conclusion: The distribution of the nurses in the sample according to age, shows that the majority of them in 40-49 years of age. Presence of male nurses more evident than female, most of them have long work period of twenty-one years and more, the majority of the participant were graduated from nursing school. The study diagnosed both safe and unsafe practices.

Recommendation The study recommends for: improving awareness of both patients and nurses to decrease over use of injection and on achievement of safety, improve vaccination coverage with hepatitis B vaccine and make it obligatory for all health care workers.

Key Words: injection, practice, safety, nurses

\section{Introduction:}

The World Health Organization (WHO)defines safe injection as one that does not harm the recipient, does not expose the health worker to any avoidable risk, and does not result in any waste that is dangerous to the community (Kotwal A. ,2005; Simonsen L. ,1999). Needle stick injuries represent the single greatest occupational hazard to medical personnel. Unsafe injections are responsible for millions of cases of hepatitis B and C, and an estimated 250,000 cases of HIV, annually (World Health Organization ,2004). Each year 16 million injections are given in developing countries. The vast majority $(95 \%)$ are given for curative care (Hustin Y. ,2003). In certain regions of the world, injections are used far more than really needed, and it is not based on rational medical practice. In some cases, as many as 9 out of 10 patients presenting to a primary health care provider receive an injection, of which over $70 \%$ are unnecessary or could be given in an oral formulation (World Health Organization ,2000). ${ }^{(2,5)}$ Tool C for the assessment of safety of injections was first implemented in 2000, and has been used in over 90 national injection safety assessment since then. Owing in part to the use of Tool C, awareness about the importance of injection 


\section{Mosul Journal of Nursing, Vol. 6, No. 1, 2018 ( 51-59 )}

safety for other invasive procedures in health services has been stimulated. To respond to that need, WHO reviewed the lessons learned during field implementation of tool $\mathrm{c}$ and applied those when designed an updated tool (Tool C-Revised): tool for assessment of unsafe practices associated with injections, phlebotomies, lancet procedures and intravenous procedures should be assessed using standardized ,representative ,simple and flexible methods that allow for reliable assessment of the country situation and for comparisons with other countries (Bolarinwa and Salaudeen ,2011). An assessment using Tool C-Revised can estimate the risk of infections associated with unsafe practice for each procedure type, determining whether a facility meets requirements for equipment, supplies and waste disposal, identifying unsafe practices and estimating the proportion of health care facilities in which practices are safely or unsafely performed (World Health Organization ,2007). Rationale: CDC estimate that $600,000-800,000$ needle stick and percutaneous injuries occur annually among health care workers in all health care fields. This is responsible for 8-16 million persons contracting Hepatitis B virus, 2.3-4 million persons contracting Hepatitis C virus and 80,000-160,000 person contracting HIV worldwide, in most cases the transmission of those agents goes unrecognized because the infection is sub clinical (Stephen L. ,2001).

The aim of the study is to determine the injection safety practices among nurses at primary health care centers.

The objectives of the study to determine whether the critical steps of injection are executed according to the recommended best practice, to identify unsafe practice that may lead to infection for both nurses and patients, to pinpoint the applications of preventive measures following accidental exposure to needle stick injuries.

\section{Methodology:}

Ethical agreement: prior to data collection, official written permission was obtained from Nineveh Health Directorate.

\section{Study Setting and Sample:}

A descriptive study was carried out among 45 nurses working at primary healthcare centers (PHC) who are involved in both preventive (vaccination) and curative (injection of drugs) services in the study area forming the sample frame. Multi stage 


\section{Mosul Journal of Nursing, Vol. 6, No. 1, 2018 ( 51-59 )}

random sampling technique was used to select 12 PHC in Mosul city. The nurses whose jobs are not directly related to health care delivery services and handling of injection were excluded from this study.

Time: Data were collected during January 2017 by the investigators who attended the health centers during the morning working hours.

Tool of the study: in order to achieve the desired aim of the present study and to determine the safe practices of injection among nurses, a special tool was used in the present study, it consisted from three parts: the first part of the tool was concerned with socio demographic data of the nurses, while the second part of the tool was an observational checklist which consisted of twenty items, each item has two options Yes and No, the rate of them 1 and 2 respectively. Through observation and interview questions, data were collected about the practice performed and facilities available for injections and about the collection and disposal of sharp wastes and needles. The third part of the tool depend on interview questions and concerned with healthy measures that has been taken after an accidental exposure to needle stick injury during daily work in the health centers. This tool was validated after exposing it to a group of experts and members of scientific committee in the department of clinical nursing. The list was rearranged and reorganized according to the opinion of the experts in order to be valid and suitable with the aim and objectives of the study. Reliability was obtained by test and retest of the tool on a sample consisted from four nurses. computation of Correlation Coefficient was applied and $\mathrm{r}=$ revealed a value of 0.8

Data analysis: the collected data were coded and tabulated then statically analyzed by using spss version (frequency and percentage) $\mathrm{x} 2$, mean scores. 
Mosul Journal of Nursing, Vol. 6, No. 1, 2018 ( 51-59 )

Results:

Table 1: Nurses demographic characteristics

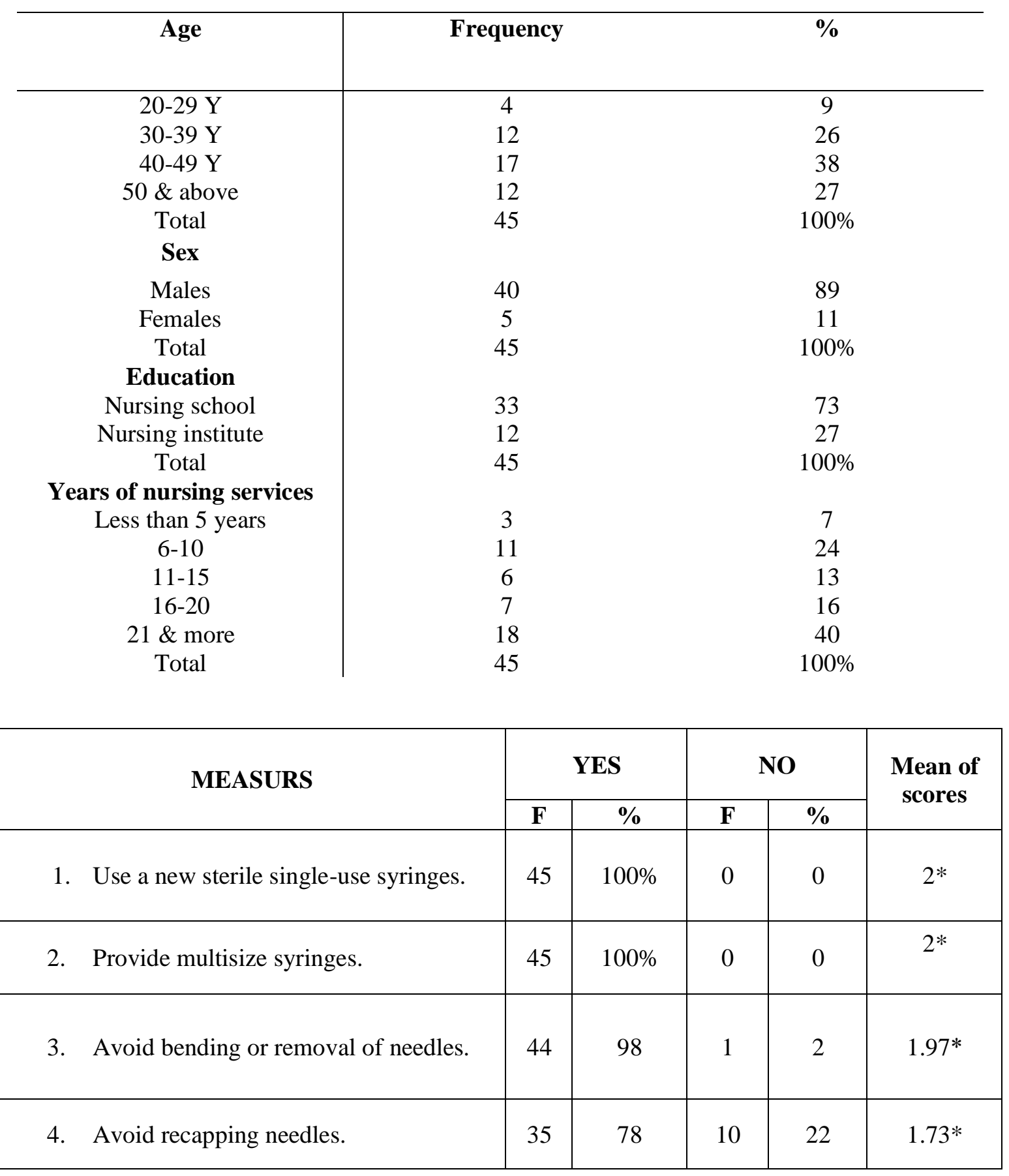

Table 2: Safe Injections and Waste Collection Measures taken by Nurses at Primary Health Care Centers

\begin{tabular}{|l|c|c|c|c|c|}
\hline 5. Dispose syringes \& needles to safety box. & 14 & 31 & 31 & 69 & 1.31 \\
\hline 6. Fill safety box up to 3/4 of the box. & 21 & 47 & 24 & 53 & 1.46 \\
\hline
\end{tabular}


Mosul Journal of Nursing, Vol. 6, No. 1, 2018 ( 51-59 )

\begin{tabular}{|c|c|c|c|c|c|}
\hline $\begin{array}{l}\text { 7. Don`t dispose vials and ampoules to safety } \\
\text { box. }\end{array}$ & 34 & 76 & 11 & 24 & $1.55^{*}$ \\
\hline 8. Close safety boxes in a closely manner. & 43 & 96 & 2 & 4 & $1.95^{*}$ \\
\hline $\begin{array}{l}\text { 9. Provide specific room for injection and arrange } \\
\text { syringes. }\end{array}$ & 41 & 91 & 4 & 9 & $1.91 *$ \\
\hline 10. Specify a team for collect safety boxes. & 43 & 96 & 2 & 4 & $1.75^{*}$ \\
\hline 11. Send safety boxes to be Buried or incinerated & 45 & $100 \%$ & 0 & 0 & $2 *$ \\
\hline $\begin{array}{l}\text { 12. Don`t remove the content of safety box to } \\
\text { another. }\end{array}$ & 45 & $100 \%$ & 0 & 0 & $2 *$ \\
\hline 13. Provide hands hygiene and skin integrity. & 14 & 31 & 31 & 69 & 1.31 \\
\hline 14. Use gloves during injection. & 3 & 7 & 42 & 93 & 1.06 \\
\hline $\begin{array}{l}\text { 15. Specify team to follow up application of safety } \\
\text { injection measures }\end{array}$ & 43 & 96 & 2 & 4 & $1.95^{*}$ \\
\hline $\begin{array}{l}\text { 16. Specify a team to follow up the complication } \\
\text { of injection. }\end{array}$ & 40 & 89 & 5 & 11 & $1.88^{*}$ \\
\hline 17. Receive training on injection safety measures. & 43 & 96 & 2 & 4 & $1.95^{*}$ \\
\hline 18. Receive at least 3 doses of hepatitis B vaccine. & 8 & 18 & 37 & 82 & 1.33 \\
\hline 19. No history of previous needle stick injuries. & 14 & 31 & 31 & 69 & $1.68^{*}$ \\
\hline $\begin{array}{l}\text { 20. Applying certain preventive measures after } \\
\text { needle stick. }\end{array}$ & 33 & 73 & 12 & 27 & $1.73 *$ \\
\hline
\end{tabular}

$\chi^{2}=368.26, \quad \mathrm{P}=0.000, \quad \mathrm{DF}=19$

* significant

Table3: Measures under taken by Nurses after Exposure to Needle Stick Injuries.

\begin{tabular}{|c|c|c|c|c|c|}
\hline \multirow{2}{*}{ Measures } & \multicolumn{2}{|c|}{ Yes } & \multicolumn{2}{c|}{ No } & \multirow{2}{*}{ M s } \\
\cline { 3 - 6 } & W & \% & F & $\%$ & \\
\hline 1. $\quad$ Washing hands thoroughly. & 31 & 100 & 0 & 0 & $2^{*}$ \\
\hline $2 . \quad$ Notify about needle stick. & & & & & \\
\hline
\end{tabular}


Mosul Journal of Nursing, Vol. 6, No. 1, 2018 ( 51-59 )

\begin{tabular}{|ll|c|c|c|c|c|}
\hline 3. & Consult a doctor. & 11 & 35.4 & 20 & 64.5 & 1.35 \\
\hline $\begin{array}{l}\text { 4. } \\
\text { exam. }\end{array}$ & Laboratory blood test for virologic & 10 & 32.2 & 21 & 67.7 & 1.32 \\
\hline 5. & Retest of blood after 6-12 weeks. & 6 & 19.3 & 25 & 80.6 & 1.19 \\
\hline 6. & Receive any treatment (antiviral). & 5 & 16.1 & 26 & 83.8 & 1.16 \\
\hline
\end{tabular}

$\chi^{2}=62.131, \quad \mathrm{P}=0.000, \quad \mathrm{DF}=5, \quad *$ significant

\section{Discussion:}

The selection of primary health care centers to be the setting for our study attributed to the type and nature of health care services provided, it includes both preventive care services that is represented by vaccination program for children below 5 years of age, child bearing women and other strata in the community, as well as curative services is represented by drugs injection, in which large amount of injections and equipment generated that increase the chance of unsafe approach that produce a major risk for both health care workers and the client unless the safety practices are achieved to minimize the risk. Table1summarize the demographic characteristics of the selected sample of nurses, distribution of them according to age show that the age group ranging between 20_60 years, more than half of them falling within the age group of 40_49 years and their mean age was $39 \pm$, this mean that they have long experience work in the field, this result appear to be supportive of other study which is show that majority of health care workers are old workers (Bolarinwa et al
,2011). While (Mahfouz and adbelmoneim ,2009) mention that female nurses in primary health care centers more than male which is against our study when we founded that male nurses represent the majority of health care workers rather than female. $95.5 \%$ of nurses had attend training sessions on safe injection approaches that is reflected clearly on their awareness and performance, which is go with the opinion of (Bolarinwa et al 2011) as they founded positive training effect on nurses performance in giving injection. Table2 shows that nurses had significant safe performance to achieve safe injection as: single use of syringes, use multisize syringes, avoid Bending needles, dispose syringes to safety box, close safety boxes tightly, provide specific room for injection, specify team to collect safety boxes, send safety boxes for buried and incinerated, don`t change safety boxes, specify team to follow up complication of injections, receive training sessions on safety injection.

On other hand the table also show unsafe practices as: don't washing hands before and after injection, don`t using gloves 


\section{Mosul Journal of Nursing, Vol. 6, No. 1, 2018 ( 51-59 )}

during injection, nurses contribute the cause of not washing hands and wearing gloves to the lack of information about the efficacy of these two measures, the need for hand hygiene and skin integrity will vary based on whether there was contact with soil, blood, or body fluids. They think that gloves are not needed for intramuscular, subcutaneous and intradermal injection which is anticipated when skin integrity is compromised by infection or other lesion (WHO, 2007).other unsafe practices diagnosed like don`t fill safety boxes to $3 / 4$ size only, dispose vials to safety box and escaping from receive full doses of hepatitis $B$ vaccine. This result go with what is founded by (Nichol and Hange, 2004) when they study the vaccination rate among health care workers and professionals and attribute the low rate of vaccination to knowledge of health care workers about vaccination requirements, and said that ongoing education of those workers will improve the access to vaccination coverage and reduce the risk of vaccine preventable diseases among them and also among patients . Table 3 the only significant safe practice after exposure to needle stick injury were: washing hands and notify about the injury within the health center, researcher founded that $68,8 \%$ of respondents had experienced a needle stick injuries during their daily work which is achieved via interview questionnaire, it's a big number when it is compared with other studies, it is four times more than needle stick injuries among nurses in Saudi Arabia (Mahfuz et al, 2009).

\section{Conclusion:}

Nurses at primary health care center performing safe and unsafe practice regarding injection safety and waste management, safe practice more than unsafe one, Significant safe practice as Single use of syringes and Using a lot of sizes of syringes in addition to Close safety boxes tightly and Avoid changing safety boxes and Continuing training on safe injection. Buried and incinerate safety boxes.. Specify team to follow up safety injection measures. Significant unsafe practice as Don`t washing hands after injection and Don't using gloves when they have skin lesion.in addition to Filling safety boxes to top and Dispose vials and ampoules to safety box.

The only significant post exposure measure founded were washing hands and notify about the exposure.

\section{Recommendations:}

In order to achieve safe and appropriate use of injections. The study recommend: Improve awareness of both health care provider (nurses)and patients and change their behavior to decrease injection overuse and achieve safety and Improve the vaccination coverage with hepatitis $B$ vaccine for all health care providers and for risky groups in the community .also 


\section{Mosul Journal of Nursing, Vol. 6, No. 1, 2018 ( 51-59 )}

Provide sufficient quantities of appropriate injection equipment and infection control supplies. In addition to recommended Setup waste management system to ensure that disposable syringes and equipment is destroyed and not reused. Continuing education and training programs for nurses to keep them up to date and aware of new safe injection policies and practices.

\section{References:}

Bolarinwa O, Salaudeen S, Aderibigbe S and Akande T. Knowledge and attitude of primary health care workers in North Central state of Nigeria. To ward safe injection, International journal of academic research, vol.3 no.3 may 2011.

Hustin Y. Best infection control practices for intradermal, subcutaneous, and intramuscular needle injections. World Health Organization, 2003, 81(7): 491500.

Kotwal A. innovation. Diffusion and safety of medical technology: a review of the literature on injection practices. Social science and medicine, 2005, 60: 1133-47.

Mahfouz A, adbelmoneim I, Daffalla A, Diab $\mathrm{M}$ and $\mathrm{Al}$ Amri H. injection safety at primary health care level in south-western Saudi Arabia. Eastern Mediterranean health journal. Vol 15, No 2. 2009.

Nichol K and Hange M. Vaccination rate among health care professionals, American journal of nursing. 104(10): 24;2004.

Simonsen L. Unsafe injections in developing world and transmission of blood borne pathgens; Review of World Health Organization, 1999, 77(10): 789800.

Stephen Luby. Injection Safety, Center For Disease Control and Prevention. Atlanta, Georgia, USA. 2001

World Health Organization. Injection practices: rapid assessment and response guide. Geneva. 2000: 1-35.

World Health Organization. Safe healthcare waste management: policy paper. Geneva. 2004

World health organization. Single use of injections devices, patient safety solutions, may 2007.

World Health Organization. Tool for the assessment of injection safety and safety of phlebotomy, Lancet procedures, intravenous injection and infusion, 16july 2007. 